\title{
Effects of Exogenous Abscisic Acid on Photosynthetic Characteristics of Chinese Cabbage Seedlings under $\mathrm{NaCl}$ Stress
}

\author{
Xuena $\mathrm{Yu}^{1, \mathrm{a}}$, Yongdong Xie $\mathrm{i}^{1, \mathrm{~b}}$, Xing Cheng ${ }^{2, \mathrm{c}}$ and Yi Tang ${ }^{1, \mathrm{~d}^{*}}$ \\ ${ }^{1}$ Institute of Pomology and Olericulture, Sichuan Agricultural University, Chengdu, Sichuan, China \\ ${ }^{2}$ College of Horticulture, Sichuan Agricultural University, Chengdu, Sichuan, China \\ ayxn4842@sina.cn, ${ }^{b} x y d c o m @ \operatorname{sina.cn,~c} 674293068 @ q q . c o m,{ }^{d}$ tangyisunguochao@sina.com \\ *Corresponding author
}

Keywords: Abscisic Acid; $\mathrm{NaCl}$ stress; Chinese cabbage; Photosynthetic characteristics

Abstract. A pot experiment was conducted to study the effects of photosynthesis of Chinese cabbage under $\mathrm{NaCl}$ stress, and different concentrations of abscisic acid (ABA) solution about 1, 5, 10 and $20 \mu \mathrm{mol} \cdot \mathrm{L}^{-1}$ was sprayed, control was sprayed water on leaves. The results showed that spraying ABA could improve net photosynthetic rate $(\mathrm{Pn})$, stomatal conductance (Gs), water use efficiency (WUE), light use efficiency (LUE), transpiration rate ( $\mathrm{Tr}$ ) and $\mathrm{CO}_{2}$ concentration of intercellular $(\mathrm{Ci})$ of Chinese cabbage under $\mathrm{NaCl}$ stress, thereby enhanced the photosynthetic capacity. Therefore, spraying exogenous ABA can improve the resistance of $\mathrm{NaCl}$ stress of Chinese cabbage, and the ABA concentration of $10 \mu \mathrm{mol} \cdot \mathrm{L}^{-1}$ worked best.

\section{Introduction}

Chinese cabbage (Brassica rapa ssp. pekinensis) is Brassica vegetables, rich in minerals and vitamins, plays an important role in greenhouse production [1]. Due to the big fat flood irrigation during protected cultivation of vegetables, soil salinity with a lot of water evaporates upward movement gathered to the soil surface, the soil widespread secondary salinization, thereby affecting the facility cabbage production quality and yield [2-3].

Abscisic acid (ABA) is a kind of plant endogenous hormones with sesquiterpene structure, which can regulate plant adaptation to environmental stress [4-5]. Numerous studies have shown that exogenous abscisic acid can effectively alleviate the damage caused by stress (high temperature [6], chilling [7], drought [8] and salt [9] etc.) to maintain normal metabolism. Xiao's study showed that exogenous ABA can significantly improve the photosynthesis of sweet potato seedlings under $\mathrm{NaCl}$ stress, and improve the salt tolerance of sweet potato [10].

Currently ABA on plant stress resistance and its application in agriculture has received increasing attention [4]. But the research of $\mathrm{ABA}$ on photosynthesis in Chinese cabbage under $\mathrm{NaCl}$ stress is rare. Therefore, this study investigated the effect of exogenous abscisic acid on photosynthetic characteristics of Chinese cabbage seedlings under $\mathrm{NaCl}$ stress, in the hope of providing a reference about Chinese cabbage cultivation in the salinized land.

\section{Materials and Methods}

Materials. The experiments were conducted at Sichuan Agricultural University $\left(30^{\circ} 42^{\prime} \mathrm{N}, 103^{\circ}\right.$ $51^{\prime}$ E), Wenjiang, China. The seeds of Chinese cabbage named quick 35 were harvested in 2014 and purchased from Chengdu, China. All chemicals used in experiments were of analytical grade. ABA was purchased from Sigma-Aldrich (St. Louis, MO, USA).

Experimental Design. Seeds were sterilized in 10\% sodium phosphate solution for 30 minutes, flushed five times in distilled water, and then placed on 9-cm-diameter Petri dishes with three layers of filter paper moistened with distilled water and germinated at $25^{\circ} \mathrm{C}$ in darkness. Seeds were considered germinated when the seed coat was broken and a radicle was visible. After germination, seeds were planted in nutrition pot filled with vermiculite and perlite, the pot was ten centimeters in diameter and height.

Seedlings were irrigated with $20 \mathrm{ml}$ Hoagland nutrient solution containing $50 \mu \mathrm{mol} \cdot \mathrm{L}^{-1} \mathrm{NaCl}$ every other day, until the experiment finished. 
When the third leaf expanded, their leaves were sprayed with 0 (control), 1, 5, 10, $20 \mu \mathrm{mol} \cdot \mathrm{L}^{-1}$ concentrations of ABA solution until foliage and dorsal dripping. Seedlings were sprayed with ABA solution every other day, and three times in total. Each treatment consisted of 10 pots with one plant per pot. Positions of the pots were randomly changed daily to minimize positional effects. 30 days after treatment, the photosynthesis of each plant was determined by using LI-6400 portable photosynthesis meter (LI-COR Inc., USA). The photosynthetic parameters of the photosynthesis meter were manual control $\mathrm{CO}_{2}$ concentration $400 \mu \mathrm{mol} \cdot \mathrm{CO}_{2} \mathrm{~mol}^{-1}$, temperature $25^{\circ} \mathrm{C}$, light intensity $1000 \mu \mathrm{mol} \mathrm{m} \mathrm{m}^{-2} \cdot \mathrm{s}^{-1}$. The determination of photosynthetic parameters were net photosynthetic rate $(\mathrm{Pn})$, transpiration rate $(\mathrm{Tr})$, stomatal conductance $(\mathrm{Gs})$ and $\mathrm{CO}_{2}$ concentration of intercellular $(\mathrm{Ci})$, and each treatment was repeated three times. Water use efficiency $(\mathrm{WUE})=$ net photosynthetic rate $(\mathrm{Pn}) /$ transpiration rate $(\mathrm{Tr})$, Light use efficiency (LUE) $=$ net photosynthetic rate (Pn) / light intensity[11].

Statistic analyses. Statistical analyses were performed using SPSS 13.0 statistical software (IBM, Chicago, IL, USA). Data were analyzed by one-way ANOVA with least significant difference (LSD) at a 5\% confidence level.

\section{Results and Discussion}

Net Photosynthetic Rate (Pn). Sprayed ABA increased the net photosynthetic rate of leaves of cabbage seedlings under $\mathrm{NaCl}$ stress (Fig. 1). When the concentrationes of ABA were 5, 10 and 20 $\mu \mathrm{mol} \cdot \mathrm{L}^{-1}$, these treatments inhanced Pn by $26.22 \%(P>0.05), 56.59 \%(P<0.05), 65.50 \%(P<0.05)$ and $42.53 \%(P<0.05)$ respectively, compared with control.

Transpiration Rate (Tr). After sprayed ABA, each treatment were significantly higher than control. With spraying ABA concentration increased, the Tr of chinese cabbage seedlings increased before decreasing, and reached a maximum, which was $133.66 \%$ of the control, when the ABA concentration of $10 \mu \mathrm{mol} \cdot \mathrm{L}^{-1}$.

Water Use Efficiency (WUE). As you can see from Fig. 3, it was not significant effects on WUE of Chinese cabbage seedlings to sprayed the ABA of $1 \mu \mathrm{mol} \cdot \mathrm{L}^{-1}$. But the high concentration of ABA promoted WUE significantly. When sprayed concentration of ABA were 5,10 and $20 \mu \mathrm{mol} \cdot \mathrm{L}^{-1}$, the WUE was increased by $20.83 \%(P<0.05), 23.82 \%(P<0.05)$ and $17.18 \%(P<0.05)$ respectively compared with control.

Light Use Efficiency (LUE). The same as Tr, with the increasing of ABA concentration, the LUE of Chinese cabbage rose rapidly at beginning, and then declined slightly. After sprayde the concentration of $10 \mu \mathrm{mol} \cdot \mathrm{L}^{-1}$, LUE reached a peak, though inhanced by $65.50 \%(P<0.05)$ compared with control, no significant with the treatments of spraying 5 and $20 \mu \mathrm{mol} \cdot \mathrm{L}^{-1}$. 


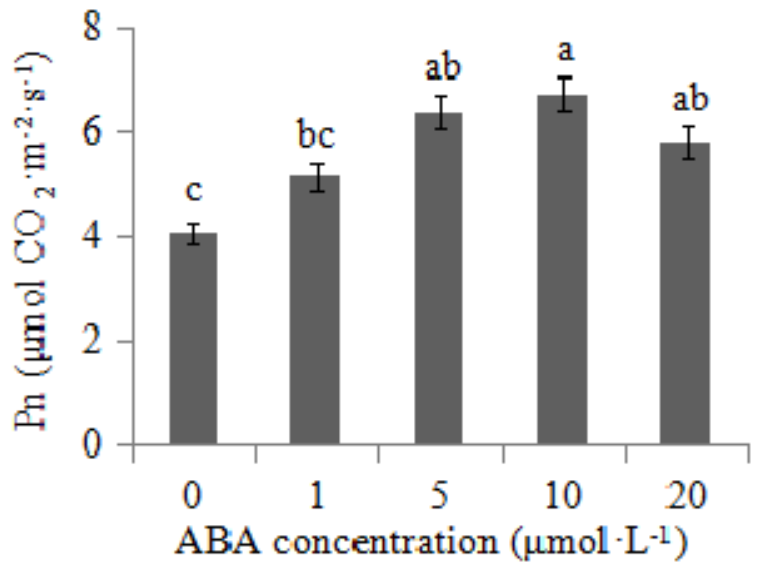

Fig. 1 Pn of ABA sprayed Chinese cabbage

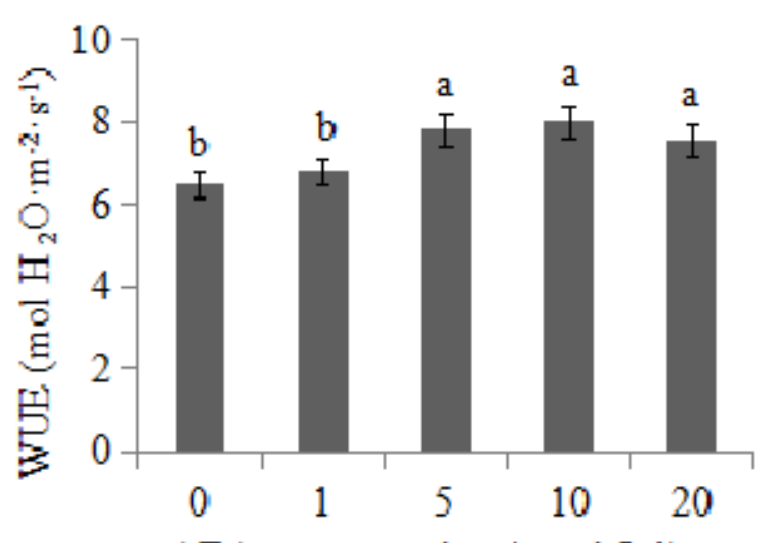

ABA concentration $\left(\mu \mathrm{mol} \cdot \mathrm{L}^{-1}\right)$

Fig. 3 WUE of ABA sprayed Chinese cabbage

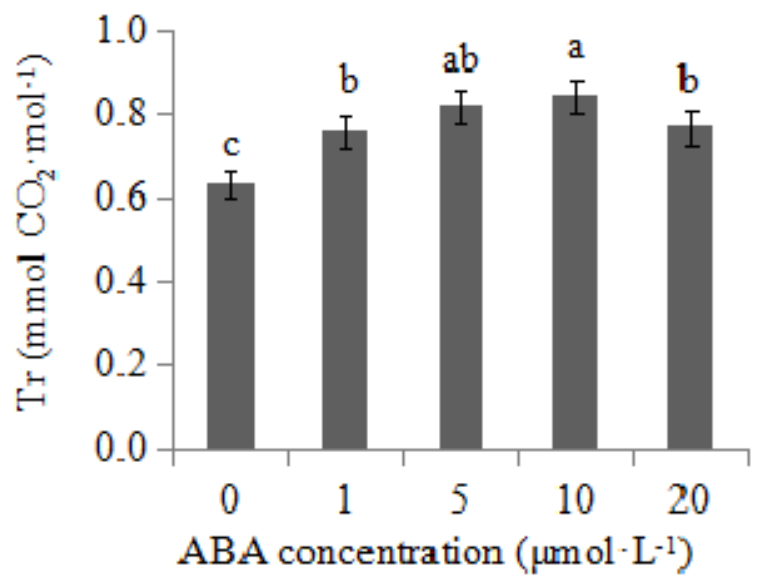

Fig. 2 Tr of ABA sprayed Chinese cabbage

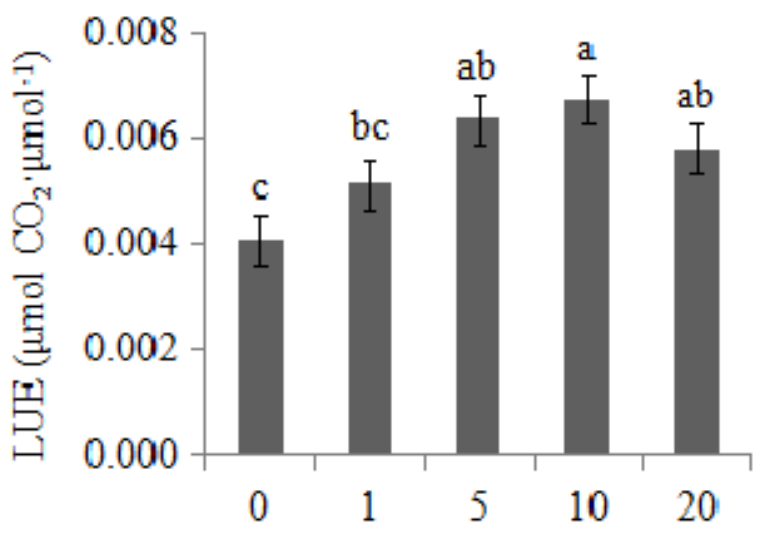

ABA concentration $\left(\mu \mathrm{mol} \cdot \mathbf{L}^{-1}\right)$

Fig. 4 LUE of ABA sprayed Chinese cabbage

Stomatal Conductance (Gs). It was clearly observed that spraying ABA significantly improved the Gs of Chinese cabbage. There were not significant difference on Gs of the treatments of spraying ABA concentration of $1,5,10 \mu \mathrm{mol} \cdot \mathrm{L}^{-1}$, and compared with control, which inhanced Gs by $205.71 \% 226.67 \%$ and $241.89 \%$ respectively.

$\mathbf{C O}_{2}$ Concentration of Intercellular (Ci). $\mathrm{Ci}$ of each treatment ABA was significantly higher than the control, but not significant difference among them.

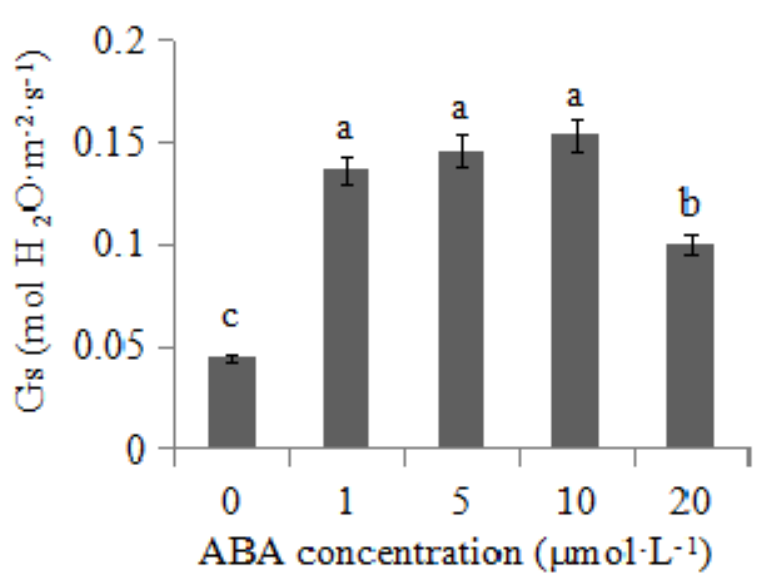

Fig. 5 Gs of ABA sprayed Chinese cabbage

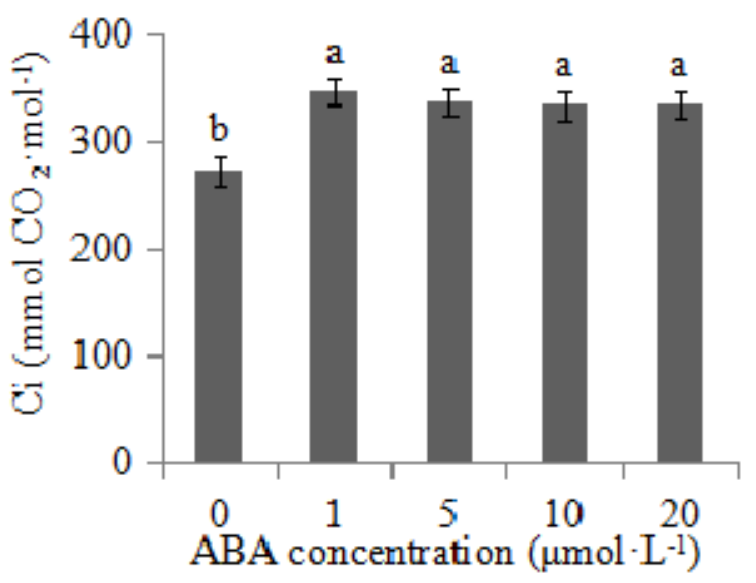

Fig. $6 \mathrm{Ci}$ of ABA sprayed Chinese cabbage 


\section{Conclusions}

Numerous studies show that ABA can improve plant antioxidant activity, alleviate membrane lipid peroxidation and protect the optical system, thereby increasing the ability of plants to salt stress $[12,13]$. The results showed that: after sprayed ABA, the Pn, Gs, WUE, LUE, Tr and Ci of Chinese cabbage seedlings were improved, and with the concentration of ABA increasing, all results are reduced after the first increase, and peaked on ABA concentration was $10 \mu \mathrm{mol} \cdot \mathrm{L}^{-1}$, except $\mathrm{Ci}$.

\section{Acknowledgements}

This work was financially supported by the Sichuan Agricultural University "Shuang-Zhi Plan" Foundation, Sichuan Provincial Department of Education Foundation (15ZA0011).

\section{References}

[1] F. F. Xu, L. M. Ye and X. Xu: Subtropical Plant Science Vol.39 (2010), p.18-20 (In Chinese).

[2] C. J. Qian, B. Sha and D. M. Huang: Shanghai Vegetables Vol.6 (2011), p. 77 (In Chinese).

[3] F. F. Xu, T. Li: Chinese Journal of Bioprocess Engineering Vol.10 (2012), p. $56-59$ (In Chinese).

[4] G. G. Hao, Z. F. Sun and L. Q. Zhang: Chinese Agricultural Science Bulletin Vol.25 (2009), p. 212-215 (In Chinese).

[5] H. Zhang: Journal of Anhui Agricultural Sciences Vol.41 (2013), p. 490-491+527 (In Chinese).

[6] R. S. Tang, H. Y. Tong and Y. H. Huang: Jiangsu Journal of Agricultural Sciences Vol.27 (2011), p. 1210-1215 (In Chinese).

[7] L. Zhang, X. M. Zhao and J. Ren: Fujian Journal of Agricultural Sciences Vol.27 (2012), p. 267-272 (In Chinese).

[8] Y. H. Ruan, S. K. Dong and L. J. Liu: Soybean Science Vol.31 (2012), p. 385-388 (In Chinese).

[9] H. Zhang, W. H. Zhang and X. L. Miao: Soybean Science Vol. 28 (2009), p. 828-832 (In Chinese).

[10]Q. Xiao, G. Wang and Y. J. Yi: Journal of Plant Nutrition and Fertilizer Vol. 22 (2016), p. 201-208 (In Chinese).

[11]X.J. Jiang, H. Wang and W. Peng: Shanxi Journal of Agricultural Sciences Vol. 54 (2008), p.56-58 (In Chinese).

[12]R. S. Tang, Y. H. Huang and X. H. Tang:Jiangsu Journal of Agricultural Sciences Vol. 25 (2009), p.856-860 (In Chinese).

[13]X. D. Wu, Z. F. Li and N. H. Zhang: Journal of Agro-Environment Science Vol. 25 (2006), p.312-316 (In Chinese). 